\title{
TRABALHO ATÍPICO E CAPITAL SOCIAL: \\ os agentes comunitários de saúde na Paraíba
}

\author{
Jacob Carlos Lima* \\ Maria do Carmo Moura**
}

\begin{abstract}
Resumo: Este artigo tem por objetivo analisar o trabalho dos agentes comunitários de saúde vinculados a dois programas governamentais: o Programa de Agentes Comunitários de Saúde e Programa Saúde da Família. Os agentes integram equipes de trabalhadores voltados à atenção básica em saúde cuja função é transmitir informações sobre higiene e saúde nas comunidades onde atuam, levantar dados sobre incidência de doenças na população e encaminhar os doentes para atendimento na Unidade de Saúde da Família. Para isso devem ser moradores da comunidade, para fazer o elo entre esta e a equipe. Constituem-se num trabalhador atípico, seja pelas características dos contratos de trabalho (temporários, terceirizados, não formalizados), seja pela posse de um capital social como competência exigida, ou seja, uma característica relacional como condição para exercer a ocupação. O trabalho dos agentes reflete as novas formas de implementação de políticas sociais descentralizadas pelo Estado e as novas formas de utilização de trabalhadores, fora do quadro do funcionalismo tradicional. A pesquisa constou de questionário aplicado a 53 Agentes Comunitários de Saúde de doze equipes do Programa de Saúde da Família nos municípios de João Pessoa, Campina Grande, Casserengue e Cacimba de Dentro; entrevistas com lideranças sindicais, enfermeiras e médicos vinculados às equipes, e gestores estaduais e municipais.
\end{abstract}

Palavras-chave: controle social, trabalho atípico, capital social, agentes comunitários de saúde.

* Doutor em Sociologia, professor do Departamento de Ciências Sociais da Universidade Federal de São Carlos; pesquisador do Grupo Interdisciplinar de Pesquisa Tecnologia e Trabalho da Universidade Federal da Paraíba. E-mail: jacobl@uol.com.br

** Mestre em Sociologia e Pesquisadora Assistente do Grupo Interdisciplinar de Pesquisa Trabalho e Tecnologia da Universidade Federal da Paraíba

Artigo recebido em 8 out. 2004; aprovado em 24 jan. 2005. 


\section{Introdução}

O objetivo deste texto é analisar uma nova categoria de trabalhadores, os Agentes Comunitários de Saúde, que integram políticas sociais implementadas na década de 90 focalizadas em populações de baixa renda. Referimo-nos aos Programas de Agentes Comunitários de Saúde, criado em 1991 e Saúde da Família, criado em 1994, pelo Ministério da Saúde.

Uma característica dessa categoria de trabalhadores está no fato de pertencerem à comunidade em que atuam, sem exigências de um conhecimento técnico específico. Este pertencimento pressuporia uma familiaridade com os problemas da comunidade, $o$ que permitiria atuar com maior eficiência e conquistar a confiança dessa população. Em outros termos, são trabalhadores selecionados a partir do capital social que dispõem, o que facilitaria os objetivos dos Programas voltados à obtenção de informações gerais de higiene e saúde e o atendimento básico em saúde da população. A partir de visitas domiciliares regulares, são recolhidas informações sobre doenças e quadros potencialmente perigosos para a saúde pública e feito o encaminhamento de doentes para o serviço médico. A confiança da população no profissional é considerada fundamental para o êxito de campanhas preventivas de vacinação e afins promovidas pelo ministério e secretarias de saúde.

Outra particularidade desses profissionais é o fato de estarem submetidos ao controle social da comunidade. A comunidade é informada dos seus direitos e da visita obrigatória dos agentes às suas residências, o que a leva a denunciar negligências e provocar o desligamento de agentes relapsos. Esse controle é facilitado pelo pertencimento do trabalhador à comunidade o que favorece o estabelecimento de laços mais estreitos com os moradores, aumentando a visibilidade sobre sua atuação. Os agentes terminam por serem procurados pela população para resolver problemas do cotidiano, nem sempre ligados à questão saúde, tornando-se, em numerosos casos, lideranças locais. 
No que se refere às relações de trabalho, estas são, em grande parte, terceirizadas. O Ministério envia a verba para a prefeitura que repassa para associações e/ou cooperativas, inexistindo vínculos empregatícios diretos com o Estado. Os contratos, em vários municípios, são apenas verbais, "de adesão", o que implica o recebimento de um salário mensal sem obrigações sociais e, para os trabalhadores, sem os direitos vinculados a um contrato formal.

Embora com diferenças por municípios, os contratos terceirizados resultam da lei de responsabilidade fiscal pela qual o Estado, em seus vários níveis, não pode gastar mais do que arrecada. Essas restrições fiscais decorrem de Constituição de 1988 e da reforma do aparelho estatal realizada nos anos 90 vinculando os gastos públicos à arrecadação. A reforma teve uma perspectiva largamente gerencial, visando enxugar o aparelho estatal na tentativa de flexibilizar a pesada máquina burocrática e reduzir custos com o funcionalismo público, acompanhando o processo de reestruturação econômica da sociedade e das políticas neoliberais do período.

Em suma, vamos analisar a situação de uma nova categoria de trabalhadores, cuja especificidade está no vínculo comunitário, no capital social entendido aqui, também, como competência, e que atende o binômio descentralização-controle social nas políticas públicas dentro do novo formato proposto para as relações de trabalho no aparelho do Estado. Essas considerações são resultado de pesquisa realizada com equipes do Programa da Saúde da Família no Estado do Paraíba no período 2001-2003, com o apoio do CNPq. A pesquisa constou de questionário aplicado a 45 Agentes Comunitários de Saúde, de oito equipes do Programa de Saúde da Família, nos municípios de João Pessoa, Campina Grande, Casserengue e Cacimba de Dentro; entrevistas com lideranças sindicais, enfermeiras e médicos vinculados às equipes, além de gestores de saúde estaduais e municipais.

Vale ressaltar que os Programas de Agentes Comunitários de Saúde e Saúde da Família foram implementados, inicialmente, no Nordeste, e a Paraíba foi um dos primeiros Estados a adotá-los. 
As características aqui apresentadas, embora reflitam sua implantação local e regional, permitem algumas generalizações acerca do trabalho dos agentes em outras regiões do País.

Para melhor entender o papel dessa nova categoria de trabalhadores, faremos uma breve discussão sobre o contexto econômico e político em que surgem as transformações no mundo do trabalho, a reforma do aparelho estatal e a recuperação do debate sobre a importância da comunidade e da interação dos indivíduos, através de suas relações de sociabilidade, como nova "competência" num mercado de trabalho em mudança.

\section{A flexibilidade no trabalho e o emprego público}

As transformações nos mundos da produção e do trabalho a partir da década de 70 do século XX têm como característica fundante a flexibilidade: dos processos produtivos, dos mercados, das relações de trabalho. Flexibilidade essa que, por sua vez, está vinculada à desregulamentação da atividade produtiva, incentivo à competitividade e ao livre mercado e, nas relações de trabalho, à redução dos contratos formais, ao fim de sua indeterminação temporal e à eliminação de limites à duração da jornada de trabalho.

A flexibilidade no trabalho assume características distintas. Pode ser considerada "positiva" a partir da valorização do conhecimento do trabalhador, maior controle do processo de trabalho, a formação continuada através da permanente qualificação, certa autonomia decisória, polivalência funcional e o trabalho em equipe. Mesmo sob o controle do capital, possibilitaria ao trabalhador uma retomada criativa do controle sobre o trabalho realizado e, conseqüentemente, maior envolvimento em sua execução. A referência é o chamado modelo japonês de gestão, conhecido também como toyotismo, que significou um repensar das formas de organização do trabalho tayloristas-fordistas centradas na separação radical planejamento/execução, com a especialização do trabalhador. $\mathrm{O}$ reconhecimento da importância do conhecimento do trabalhador dos 
processos de trabalho e sua relativa desespecialização tornaram-se um fator de aumento da produtividade e qualidade do trabalho realizado.

A difusão do toyotismo no ocidente e sua adaptação através do que ficou conhecido como reestruturação produtiva, resultou numa mescla de formas de organização do trabalho na qual a autonomia e o conhecimento do trabalho foram acompanhados de formas tayloristas ou mesmo pré-tayloristas em uma infinidade de combinações cujo objetivo tem sido a redução de custos. $\mathrm{O}$ crescimento da terceirização da produção constituiu-se numa faceta desse processo, com a criação de redes empresariais voltadas para o aumento da competitividade através do "enxugamento" e "focalização" no produto principal, resultando na eliminação da força de trabalho considerada desnecessária, seja pelas novas tecnologias, seja pelas novas técnicas de gestão. Com isso assistimos o reverso da flexibilização "positiva": a precarização do trabalho, com a desregulamentação das relações de trabalho, a supressão de direitos adquiridos que compunham a relação salarial, o fim da estabilidade no emprego, a adoção de formas parciais ou temporárias de utilização da força de trabalho, a eliminação do contrato formal de trabalho e sua substituição por formas variadas de prestação de serviços. Temos, então, a multiplicação de formas atípicas de relações de trabalho, fora do modelo estabelecido pela relação salarial: contratos temporários, informalidade no trabalho e formas associativas que visam desonerar a gestão e utilização da força de trabalho.

O emprego público pode ser considerado uma das últimas trincheiras do emprego "fordista", se o pensarmos enquanto relações de trabalho estáveis, com contratos por tempo indeterminado e direitos sociais dentro da perspectiva do chamado "Estado providência". Mesmo considerando que, entre nós, este Estado foi parcial e restrito a algumas categorias de trabalhadores, o emprego público se revestiu da aura da estabilidade, sem desconsiderar sua heterogeneidade nos diversos níveis de governo. No Brasil, na instância federal, os poderes Executivo, o Legislativo e Judiciário, atingiram elevado grau de racionalidade burocrática, situação existente em menor escala nos 
âmbitos estaduais e municipais. Os concursos públicos e as carreiras profissionais compõem o cenário de um mercado de trabalho protegido com direitos sociais diferenciais (comparativamente aos trabalhadores das empresas privadas), ao lado de contratos temporários que marcaram e marcam historicamente o serviço público: cargos de confiança, professores emergenciais, médicos, entre outros profissionais, vinculados a contextos específicos, gestões governamentais, etc. Entretanto, o concurso público sempre esteve no horizonte, e os trabalhadores, quando temporários, sempre pressionaram o poder público para acertar sua situação no quadro do funcionalismo, seja por concurso, seja por "decretos" arranjados clientelisticamente.

Mas o Estado não passou imune à reestruturação econômica. A idéia de desregulamentação e flexibilização juntou-se à interpretação neoliberal de "enxugamento" do Estado. A crise fiscal dos anos 70, o crescimento do pagamento das obrigações sociais pelos Estados de Bem-Estar, colocaram em cheque uma forma de organização estatal marcada pela regulação das atividades econômicas, pelo planejamento centralizado, pela mediação dos conflitos sociais e sua atenuação através de direitos sociais aos trabalhadores. A idéia de reforma do Estado como necessidade de ajuste fiscal, de saneamento das contas públicas, de retirada das atividades econômicas através da privatização de empresas e serviços sobre seu controle, foi acompanhada do debate sobre a descentralização das atividades estatais e da co-responsabilização das diversas instâncias governamentais e da sociedade através da participação de grupos sociais organizados na definição, implementação e fiscalização das políticas públicas. Uma nova economia exigiria um novo Estado, mais enxuto, mais gerencial, mais eficaz. As experiências de reformas neoliberais implementadas, embora não tenham se destacado pelo seu êxito, questionaram a eficácia das formas anteriores de organização da atividade estatal, na qual a centralização passou a ser vista como grande problema. 


\section{A reforma do Estado: descentralização, democratização e controle social}

Em sua análise sobre o Estado na "sociedade em rede", Castells (1999, 1999a) afirma que a globalização do capital e a interdependência dos mercados financeiros exigem estabilidade monetária e conversibilidade das moedas. Isto implica uma tendência para condicionar a integração global à harmonização de políticas macroeconômicas e convertibilidade de moedas, o que resulta numa dependência dessas políticas de critérios orçamentários e numa política monetária dependente dos mercados financeiros. O controle dos gastos públicos passa a ser prioritário frente aos investimentos, limitando a intervenção estatal na economia e imprimindo novo formato às políticas públicas.

O Estado passaria, então, a coordenar "nós de uma rede" através das diferentes instâncias políticas, nas quais governos locais e regionais teriam maior flexibilidade de adaptação aos fluxos globais. Também por estarem mais próximas dos cidadãos, essas instâncias possibilitariam à população maior controle das políticas estatais e do uso das verbas públicas. A descentralização ampliaria o espectro democrático ao possibilitar a inserção direta dos cidadãos no debate sobre formulação e implementação de políticas públicas, ampliando seu poder de intervenção e de acesso a direitos.

O local tornar-se-ia o espaço por excelência da democracia e da participação. Embora seja, igualmente, o nível mais corrupto da administração pela força das redes pessoais, possibilitaria um maior controle social representado pela maior proximidade entre governo e cidadãos. Nesse contexto, a esfera municipal assumiria nova dimensão em sua relação com os cidadãos, com o surgimento de novos atores sociais e novas relações sociais decorrentes da mudança de qualidade da participação política, tornando-se necessário o estabelecimento de novos espaços no poder local através de conselhos, com a participação de representantes da comunidade que decidiriam sobre as prioridades de investimentos e seu controle. 
A descentralização seria uma proposta de ação e até mesmo uma opção político-administrativa de aproximar o local do global, estabelecendo novas regras de relações entre o federal, o estadual e o municipal, transferindo competências e atribuições de outras esferas para os municípios, fortalecendo e aumentando suas potencialidades. O município, nessa perspectiva, passa a ser o locus central na busca de soluções dos problemas dos cidadãos e patrocinador de uma maior interação entre o Estado e a sociedade.

O Estado seria, dessa forma, o instrumento de que os cidadãos disporiam para controlar a globalização, e sua reforma se constituiria na ocasião de implementar a mudança social, dotando-o de capacidade para intervir na busca do bem comum.

A descentralização possibilitaria a substituição do Estado pela sociedade em diversas situações, dando a este maior direcionamento e flexibilidade em sua organização e atuação, assumindo um caráter negociador e interventor em situações que demandem uma atuação mais efetiva. O Estado teria um papel de coordenador dos vários níveis de governo, articulado a organizações da sociedade civil. A reforma pressuporia, igualmente, a modernização tecnológica e a transparência administrativa com o fim do funcionalismo público, tal como se apresenta na atualidade, e sua transformação em agentes de administração.

As propostas de Castells, em certa medida, sintetizam o debate sobre reforma do Estado nos anos 90 no Brasil, com o autor participando de seminários organizados pelo Ministério da Administração dentro do projeto do governo federal de reforma e modernização do aparelho estatal para adequá-lo aos ditames da globalização. ${ }^{1}$

Essas considerações, embora preliminares e longe de pretender dar conta do debate sobre reforma do Estado, permitem compreender a implementação de algumas políticas sociais pelo Estado brasileiro nesse período. Basta lembrar que a Constituição de 1988, conhecida como constituição cidadã, resultado da luta pela redemocratização da sociedade brasileira, teve na descentralização um dos seus 
aspectos de destaque. Descentralização pensada como democratização com a co-responsabilização dos vários níveis de governo e pela ampliação dos canais de participação social dos setores organizados da sociedade na formulação, controle e fiscalização das políticas públicas.

Atendia aos interesses de democratização defendidos pela esquerda política com a participação, na Constituinte, de numerosos movimentos e organizações sociais, e da direita, através da reforma do Estado voltado à eficácia e ao enxugamento do aparato estatal, com a crise fiscal do Estado Providência e a retomada do discurso liberal como saída para a crise. Poderíamos afirmar que essa busca por maior participação decorreria da relativa perda de legitimidade dos parlamentos e dos partidos políticos como garantidores do caráter público das decisões estatais, dado seu envolvimento em escândalos e acusações de corrupção e mau gerenciamento da coisa pública. Dessa forma, a reforma das instituições de representação política deveria ser complementada por formas de participação direta dos cidadãos que extrapolariam o ato de simplesmente votar (Andrade, 2001). É o que Bresser Pereira \& Grau (1999, p.23) chamam de renovação da institucionalidade política, que teria a dimensão de accountabilitty (a demanda frente às instituições políticas e à cidadania como sujeito político direto) e o controle social através da participação social na formulação e/ou controle de políticas setoriais.

O controle social seria definido como a forma pela qual a sociedade controla o Estado, para além das formas clássicas de representação política, garantindo regulações sociais através de organismos e instituições não estatais como movimentos sociais organizados, organizações não governamentais, associações e conselhos comunitários. O fundamento do controle social seria a recriação do espaço público com a proteção do direito à coisa pública.

Para a efetivação desse controle, a participação da comunidade é considerada fundamental. As tentativas para fomentar essa participação não são recentes. Desde os anos 70, organismos internacionais de financiamento já recomendavam a participação 
comunitária para comprometer a sociedade com o governo e criar novas parcerias. Desde essa época, o governo brasileiro utilizava esse discurso, embora sem grande ressonância, principalmente no meio rural, através de cooperativas de produtores e outros programas nos quais o associativismo era incentivado de forma intermitente e desvinculado das diversas "culturas locais", com programas pontuais que rapidamente eram abandonados. É desse período a recuperação do discurso sobre a importância dos laços comunitários que poderiam ser instrumentalizados na implementação de políticas públicas.

\section{Comunidade e capital social}

A preocupação com a comunidade vincula-se ao sentido de solidariedade e identidade comum que, em tese, a comunidade teria e que poderia levar a um rompimento com o individualismo dominante, promovendo uma maior integração social. Nos anos 80, inseriu-se no debate já referido sobre democracia "descentralizada" frente à crise do modelo keneysiano, a democracia associativa de inspiração norte-americana, na qual mercado, Estado e comunidade superariam a crise do Estado. Nos anos 90, o debate sobre comunidade incorpora a noção de associativismo, pluralidade, identidade e solidariedade, condição da renovação democrática e de eficácia governamental. Nessa perspectiva situam-se programas de acompanhamento de políticas públicas, conselhos municipais (saúde, educação, assistência à criança e ao adolescente, agricultura familiar), orçamento participativo e organismos de composição paritária entre governo e sociedade (Andrade, 2002).

Outro fator a destacar na discussão sobre comunidade ${ }^{2}$ e controle social é a sua adequação à flexibilidade das novas formas de trabalho. O conceito de controle social, desde Durkheim, ${ }^{3}$ evidencia o caráter coercitivo das normas sociais e as sanções para aqueles que não as obedecem, que vão das regras informais ao estabelecimento legal do que é crime em determinada sociedade. Refere-se à interiorização das normas e valores do grupo ou mesmo de uma cultura. $\mathrm{O}$ caráter comunitário presente no controle social 
estaria no caráter territorializado da comunidade que criaria identidades pelas condições sociais semelhantes, necessidades e carências comuns. Em situações de trabalho, sua aplicação garantiria a interiorização de uma disciplina que possibilitaria, ao mesmo tempo, a autonomia e individualização na realização de tarefas acompanhadas pelo grupo ou equipe, em ambientes de trabalho mais ou menos fechados, e pela comunidade em situações de atendimento em programas e/ou políticas públicas.

O capital social se agrega ao sentido da comunidade a partir dos laços estabelecidos entre os membros que a integram, laços esses com níveis de formalidade distintos, mas caracterizados por um conhecimento comum e sentimento de participação. O capital social, conceito utilizado inicialmente por Bourdieu (1986) e desenvolvido e aplicado por sociólogos norte-americano como Colleman (1990) e Putnam (2002) entre outros, enfatiza que as redes sociais informais e o estabelecimento de relações de confiança entre os participantes dessas redes permitem a estes usufruírem vantagens propiciadas por esse conhecimento. Um exemplo é a importância desse capital na obtenção de informações sobre o mercado de trabalho através de conversas informais com amigos, conhecidos ou parentes. E não apenas ao mercado de trabalho, mas em diversas situações da vida econômica nas quais as normas de reciprocidade presentes nas relações sociais resultariam em confiança que permeariam e extrapolariam a racionalidade burocrática (Colleman, 1990; Granovetter, 1995). Ou seja, um capital relacional resultante de um conjunto de normas de reciprocidade, informação e confiança presentes nas redes de sociabilidade informais da vida cotidiana.

Utilizar capital social como uma competência específica no mercado de trabalho, pode ser considerado uma temeridade, pelo caráter polêmico e mesmo impreciso do conceito, entretanto possibilita refletir sobre o "novo perfil de qualificação flexível" no qual esperase do trabalhador, além de escolaridade mínima, uma capacidade de adequação a novas situações, de resolver por sua conta problemas surgidos no trabalho, capacidade de interpretar as informações recebidas, além de forte capacidade relacional para o trabalho 
em equipe e, no caso estudado, relacionamento com a população atendida. Em outros termos, a noção de competência implicaria uma recuperação de componentes socioculturais e de subjetividade do trabalho, nos quais as conotações sociais e político-ideológicas são explicitamente valoradas (Manfredi, 1998).

Capital social pode significar, ainda, controle social através das normas e sanções pelas quais a comunidade pode ser beneficiada, como inibição ao crime ou a comportamentos considerados nocivos à comunidade, podendo facilitar, segundo Colleman (1990), o desenvolvimento de movimentos sociais (pela utilização ou abandono das normas) e formas associativas que a beneficiariam.

O associativismo e o engajamento cívico dos cidadãos seriam dimensões constitutivas do capital social e poderiam auxiliar no desenvolvimento social, a partir do incentivo de agências públicas ao envolvimento da sociedade, através de suas organizações, para o debate, implementação e controle de políticas públicas. O debate sobre capital social foi assumido por órgãos multilaterais voltados para o desenvolvimento, como o Banco Mundial, inserindo-se nas propostas de reforma do Estado, de sua descentralização e envolvimento da sociedade na elaboração e controle de suas políticas.

Andrade (2002) questiona o peso político efetivo da comunidade e das possibilidades de mobilização do capital social, considerando a falta de tradição comunitária e associativa no Brasil. Ao contrário da comunidade cívica de Putnam (2002), que explicaria as diferenças sociais do norte e do sul italianos e mesmo de sua importância na sociedade norte-americana, com forte caráter associativo, no Brasil, ao contrário, a não participação da maior parte da população inserese na cultura política nacional marcada por pactos de elites e mudanças de cima para baixo. Isso explicaria a dificuldade de implementação de políticas participativas entre nós, ou, pelo menos, a sua lentidão, pois implicaria mudanças culturais significativas. ${ }^{4}$ 


\section{O trabalho no Programa de Agentes Comunitários de Saúde (PACS) e o Programa Saúde da Família}

A Constituição Federal de 1988 estabeleceu o Sistema Único de Saúde (SUS) com cinco princípios: universalização, integralidade, descentralização, hierarquização e participação popular. A proposta do SUS coroava o debate sobre a necessidade de um novo modelo da assistência à saúde no qual a medicina comunitária apresentavase, para o movimento de reforma sanitária que capitaneava esse debate, como um modelo alternativo de prestação de serviços de saúde e como condição para garantir igualdade e universalidade no atendimento.

Uma das primeiras estratégias para essa mudança foi a criação do Programa de Agentes Comunitários de Saúde (PACS), numa perspectiva prevencionista, elaborado pelo Ministério da Saúde e com orientação do Fundo das Nações Unidas para a Infância (Unicef). Significou, inicialmente, um caminho para resolver a dificuldade de acesso aos serviços e a falta de: credibilidade na prestação dos serviços públicos de saúde; de informações sobre cuidados básicos de saúde e de resolutividade na atenção à saúde. Contribuía para essa situação, a ausência de identificação entre as comunidades e os serviços de saúde. Os Agentes Comunitários foram pensados para serem mediadores e articuladores entre o serviço e a comunidade.

O Nordeste foi uma das primeiras regiões a implantar um projeto do PACS, em 1991, por ser considerada a região mais pobre do País, e deter, nos anos oitenta, uma alta taxa de mortalidade infantil. Um fator central considerado na elaboração do programa foi o baixo nível de informação e orientação da população, considerado responsável pelo agravamento da situação. A dificuldade do acesso à informação por parte das comunidades, principalmente pelas mulheres, foi tido como fator a ser priorizado, visto que muitas doenças poderiam ser evitadas sem recorrer a socorros médicos, mas, simplesmente, através de cuidados caseiros. Caberia aos Agentes Comunitários de Saúde levar essa informação à comunidade. 
O PACS utilizou experiências de programas anteriores implementados em várias regiões do país, como Médico da Família, de Niterói, os Agentes Pastorais (da criança) da Igreja Católica (voluntário), as visitadoras sanitárias da Fundação SESP, entre outras de menor dimensão. Podemos dizer que a experiência mais sistematizada, e talvez a mais próxima do PACS, foi a do Ceará com o Programa de Agentes de Saúde do governo estadual a partir de 1987, inicialmente um programa emergencial para um período de seca e que, dado seu êxito na redução da mortalidade infantil, foi transformado em programa permanente.

Seus fundamentos encontram-se no movimento sanitarista e em experiências como os médicos pés descalços da China e similares em Cuba, Canadá e Inglaterra. Sua lógica baseia-se na prevenção, voltada à informação de noções básicas de higiene para o atendimento materno infantil e controle através de registro da população atendida por visitas domiciliares. Posteriormente, essas funções foram expandidas para a prevenção de doenças e promoção da saúde da comunidade.

Os agentes integravam o PACS sob a supervisão de um enfermeiro que era responsável pelo treinamento, monitoramento e controle da equipe. $\mathrm{O}$ número de agentes por município variava de acordo com a população e aos agentes cabiam as visitas domiciliares e o encaminhamento dos enfermos para o atendimento médico. $\mathrm{O}$ número de famílias sob a responsabilidade dos agentes nas zonas urbana e rural foi fixado considerando-se a densidade demográfica diferenciada nas duas áreas, ficando em 100 a 150 na zona rural e 200 a 250 na zona urbana. A enfermeira supervisionava os agentes, mas estes não tinham uma ligação com os centros de saúde, quando estes existiam. Havia um acompanhamento das famílias, mas não havia para quem encaminhar as soluções.

Em 1994 foi implantado o Programa de Saúde da Família. Neste, as Unidades Básicas de Saúde passaram a ser Unidades da Saúde da Família com a proposta de privilegiar a atenção básica, fazendo a maior parte dos atendimentos na própria unidade e 
incorporando ações intersetoriais como educação, saneamento e meio ambiente, no sentido de melhoria da qualidade de vida da população assistida (Ministério da Saúde).

Os agentes foram sendo incorporados às equipes de saúde da família compostas por cinco ou seis agentes, o médico da família, o enfermeiro (que além de prestar assistência à população, controla o trabalho dos agentes), e, conforme o local, por auxiliares de enfermagem e outros profissionais, como odontólogos e assistentes sociais. Os agentes continuam com as obrigações das visitas domiciliares e encaminhar pacientes ao enfermeiro e ao médico que, por sua vez, os encaminham para serviços de maior complexidade.

Cada equipe passou a ser responsável pelo atendimento aproximado de mil famílias ( 2.400 a 4.500 pessoas de uma determinada área), que deveriam receber pelo menos uma visita mensal do agente (média de 575 pessoas por agente/ou 100 a 150 famílias). Essas visitas seriam realizadas pelos agentes a partir de uma jornada de trabalho de oito horas por dia. Os membros da equipe (médicos e enfermeiros) deveriam morar no município e os agentes, ser residentes na comunidade atendida pela unidade.

O processo de trabalho das equipes pressupõe reuniões semanais de planejamento das atividades nas quais os problemas são discutidos, o atendimento dos pacientes encaminhado e, no caso dos agentes, o cadastro dos moradores, sua atualização, visitas domiciliares com a implementação de informações básicas de higiene e saúde, encaminhamento de doentes aos postos e agendamento de consultas. O treinamento continuado dos profissionais é realizado através de programas das secretarias estaduais de saúde que englobam todos os profissionais das equipes.

O governo federal repassa aos municípios a verba para o pagamento dos agentes e da equipe. Geralmente, a secretaria do Estado funciona como órgão coordenador do projeto, podendo ser ainda formador e selecionador dos agentes. O enfermeiro e o médico são contratados pelas prefeituras. O número de agentes significa um número de postos de trabalho alto conforme o município, e que escapa, 
em grande parte, do controle político dos prefeitos que, em tese, não interfeririam na seleção. Entretanto, torna-se cada vez mais objeto de desejo dos prefeitos e políticos locais pelo potencial político do recrutamento e mesmo na utilização do trabalho dos agentes.

Na seleção dos agentes, exige-se alfabetização, ${ }^{5}$ que sejam maiores de idade e morem na comunidade há, pelo menos, dois anos. $\mathrm{O}$ contrato da equipe pode ser por termo de adesão, sem vínculo algum, ou contrato com cooperativas, OSCIPs (Organizações da Sociedade Civil de Interesse Público), Associações Comunitárias, ONGs, CLT e como funcionários públicos.

Nogueira, Silva e Ramos (2000) destacam as formas de vinculação dos Agentes Comunitários de Saúde que refletem, em certa medida, as formas de vinculação utilizadas nas contratações pelo Estado: a) estatutário por concurso público; b) contrato pela CLT por prazo indeterminado através de contrato direito via secretaria municipal, indireto via empresa, indireto via associação; c) cargo comissionado; d) contrato excepcional por tempo determinado. Nessas formas, o trabalhador teria seus direitos trabalhistas garantidos. As outras formas de prestação de serviços com contratos temporários, entretanto, são majoritariamente dominantes. Em função dos limites de comprometimento fiscal, na maioria dos municípios, o contrato é por dois anos com alguma associação, com um termo verbal de adesão renovado constantemente, mas sem contrato formal, representando cerca de $80 \%$ dos "contratos". Em algumas equipes são utilizados funcionários públicos regulares deslocados para as Unidades de Saúde da Família, como enfermeiros ou funcionários de apoio.

As associações de trabalhadores do PACS têm reivindicado o contrato como funcionários estatutários. Entretanto essa reivindicação enfrenta obstáculos legais, decorrentes da reforma do Estado, já referida, que estabeleceu limites às despesas com pessoal. Estabeleceu ainda, as carreiras tipicamente de Estado nas áreas financeiras, jurídicas e de segurança pública, sujeitas a concursos públicos e estabilidade no emprego. Nas demais carreiras, as formas de contratação seriam preferencialmente por tipos flexíveis de relação 
institucional via organizações sociais ou entidades de interesse público (Nogueira, Silva \& Ramos, 2000).

Neste contexto, os ACS perfazem, em alguns casos, dez anos como trabalhadores "precários", sem nenhum tipo de contrato. Se considerarmos os agentes do programa cearense, esse tempo passaria de 14 anos.

Outras questões de ordem corporativa têm dificultado a institucionalização de vínculo empregatício no Programa Saúde da Família: brigas intercorporativas de enfermeiros que consideram os agentes uma ameaça à sua atividade e associações médicas que brigam contra a contratação de profissionais estrangeiros, embora pouco se manifestem sobre a recusa de profissionais "nacionais" se deslocarem dos grandes centros para os sertões do País. Entretanto, essas questões são menores frente a um quadro de mudanças institucionais no mercado de trabalho que rompem com padrões estabelecidos pela relação salarial e na qual os funcionários públicos lutam para permanecer.

A credibilidade é tida como básica para a atuação dos agentes. Ser confiável e ter liderança são requisitos desejáveis para o agente. Esses critérios tornam o agente um trabalhador especial cujo capital social, conhecimento da comunidade e da realidade local, liderança e solidariedade se constituem um a priori das qualificações técnicas, adquiridas num segundo momento com o treinamento continuado das equipes. Essas qualificações os diferenciam radicalmente do servidor público tradicional, estável e submetido a concurso público e a um regime disciplinar característico (Nogueira, Silva \& Ramos, 2000).

Segundo Sousa (2001), recuperando o debate sobre a implantação do PACS, a posição dominante no planejamento da proposta do Programa era que, dado o papel esperado desses trabalhadores - os agentes comunitários - como interlocutores entre a comunidade e os serviços locais de saúde, não poderiam ser funcionários públicos. Considerava-se que o vínculo comunitário seria rompido pela cultura institucional do funcionalismo, com afastamento 
progressivo da comunidade e o conseqüente afrouxamento do controle social previsto no programa.

Estudando o programa de Agentes de Saúde do governo cearense, iniciado em 1987, e precursor, em grande medida, do PACS, Tendler reforça essa tese afirmando que o diferencial do programa, e sua inovação, estaria na exigência dos laços comunitários dos agentes com a população e pelo fato de não terem a estabilidade dos funcionários públicos. Os agentes terminariam por se constituir em lideranças locais, sendo reconhecidos pelos habitantes como intermediários frente ao Estado, levando reivindicações destes não apenas ao posto de saúde, mas a outras instâncias governamentais. Além do salário mínimo que ganhavam, esses trabalhadores seriam motivados pelo prestígio e status que passavam a ter na comunidade. Dessa forma, esse pertencimento ao local e o controle da comunidade sobre o trabalho do agente poderiam explicar o maior envolvimento desses trabalhadores com o programa, assim como maior participação da comunidade que se sentiria atendida, mesmo que parcialmente, pelo Estado (Tendler 1997).

Esses critérios, destacados por Tendler, estão presentes em documentos do Ministério da Saúde sobre o PSF e depoimentos de técnicos, médicos e enfermeiros que destacam a importância da inserção comunitária e capacidade de liderança dos agentes de saúde no sucesso do Programa. O controle social também é valorizado, refletindo a progressiva participação da comunidade na fiscalização do funcionamento das equipes. Reclamações contra médicos e enfermeiros ${ }^{6}$ são comuns, assim como desligamentos de agentes por falta de cumprimento das atividades a partir de denúncias das comunidades ou a constatação, pelas próprias equipes, de desvios de condutas de membros das equipes que comprometem o trabalho, como furto e distribuição de medicamentos, não observância do número de visitas, não realização das visitas, cobranças por serviços prestados, entre outros.

Depoimentos sobre a valorização do trabalho dos agentes e das equipes pela comunidade também são recorrentes. Uma 
enfermeira que trabalhava em uma unidade do PSF no município de Camaragibe, na região metropolitana do Recife, área periférica e extremamente violenta, relatou que em determinados morros, nos quais nem a polícia entrava, os agentes eram respeitados por todos e os "controladores" dos morros avisavam que agentes não "poderiam" ser removidos. Não apenas os agentes, mas todos os membros da equipe eram "protegidos" nos morros, assim como os postos de saúde, que raramente eram alvos de vandalismo ou roubos.

O sucesso do programa não é geral, assim como o controle comunitário proposto. A adesão dos municípios aos programas pressupõe a existência de conselhos locais e municipais de saúde, os quais os prefeitos tentam controlar ao máximo indicando seus membros e, quando conseguem, estes conselhos tornam-se meramente cartoriais, sem nenhuma operacionalidade. Médicos e enfermeiros também são contratados - muitas vezes - entre parentes dos prefeitos ou seus indicados. Nem sempre cumprem as oito horas de serviço e moram, em grande parte, nas capitais ou fora dos municípios em que trabalham. Em alguns municípios, a dificuldade de contratação de médicos é grande e as equipes passam largos períodos sem contar com esses profissionais.

As tentativas de fraudes também são comuns e o Ministério da Saúde tem suspendido o repasse de verbas a prefeituras por irregularidades em sua utilização, evidenciando uma cultura política na qual o clientelismo e a utilização do dinheiro público para o benefício de grupos politicamente dominantes continua vigorando.

O mesmo podemos dizer sobre "culturas profissionais" do médico e do enfermeiro o que pode explicar o pouco envolvimento de alguns profissionais, mesmo considerando os salários relativamente altos recebidos $(\mathrm{R} \$ 2.500,00$ para os enfermeiros, até $\mathrm{R} \$ 6.000,00$ para os médicos) em alguns municípios. Essas culturas são constituídas pela formação curativa, de consultório ou de hospital dos profissionais, que mantém pouco contato com as comunidades, além da tendência de manterem diversos empregos para aumentar a renda o que contribui para descaracterizar o programa. 
Igualmente difícil tem sido a implantação do PSF nas capitais de Estados e grandes cidades. $\mathrm{O}$ grau de violência dificulta o trabalho dos Agentes Comunitários de Saúde e estes são vistos, pelo menos inicialmente, com desconfiança pela população. Os processos seletivos organizados autonomamente pelas prefeituras (que, dependendo do tamanho da cidade e da infra-estrutura de saúde, têm autonomia para isso), muitas vezes desconsideram a vinculação comunitária, favorecendo fraudes na comprovação pelos candidatos dessa vinculação, e, também, as indicações políticas.

Mesmo assim, o programa tem dado resultados positivos na redução de índices de mortalidade infantil e de atendimento primário a população. Em locais onde prefeitos se envolvem seriamente e a comunidade se mobiliza, os resultados tem sido melhores, com maior controle sobre as equipes e o envolvimento efetivo da população na cobrança de seus direitos de atendimento e da qualidade dos serviços.

\section{Os Agentes Comunitários de Saúde na Paraíba}

Na Paraíba, o PACS foi implantado no ano de 1991 em 85 municípios. Este total representava quase $50 \%$ dos municípios do Estado que, naquela época, eram 171. Mesmo com objetivos claros, a organização do PACS foi complicada considerando injunções políticas diversas, a heterogeneidade dos municípios e a complexidade do processo de descentralização, tendo avançado muito pouco até 1994. A partir desse ano, foi retomado e intensificado o processo de implantação, chegando a uma cobertura de mais de $96 \%$ dos municípios em 1997. O Estado passou a ter mais 42 municípios, totalizando 223 a partir de 1996, dos quais 11 tinham apenas o PACS e 212 o PSF. Em termos percentuais, 73,9\% dos municípios paraibanos estavam cobertos pelo PSF, ou seja, 46,6\% das famílias que dependiam dos serviços públicos de saúde. Eram 842 equipes do PSF em todo o Estado, podendo ser encontradas nos municípios tanto equipes do PSF como do PITS (Programa de Interiorização de Trabalhadores em Saúde) ${ }^{7}$ (Paraíba. SIAB/SES, 2003). O número 
de pessoas que recebiam assistência do PSF, do PITS e do PACS em todo o Estado era de 613.874 (Paraíba. Relatório... 2002).

Os Agentes Comunitários de Saúde totalizavam 6134 trabalhadores no Estado em junho de 2003. Em pesquisa exploratória realizada com 53 agentes de doze equipes nas cidades de João Pessoa, Campina Grande, Cacimba de Dentro e Casserengue foram levantadas algumas características do perfil desses profissionais: eram majoritariamente mulheres (47), com segundo grau completo ou incompleto (32), idade entre 18 e 30 anos (36); casada(o)s e solteira(o)s em proporções semelhantes; presença significativa de ex-donas de casa (12), estudantes (8, em João Pessoa e Campina Grande), ex-trabalhadores rurais (13, em Casserengue e Cacimba de Dentro) e os demais com ocupações variadas.

A presença feminina dominante pode ser explicada pela natureza do trabalho no qual a confiança na agente termina sendo maior. A focalização inicial dos programas no pré-natal e em cuidados com recém-nascidos estabeleceu uma relação mais fácil entre as mulheres da comunidade e as agentes. Cerca de 43 agentes estavam há mais de dois anos na atividade. Tornaram-se agentes por falta de opção de emprego na região (20), pelo tipo de trabalho (23) e por militância comunitária (10).

Todos(as) tinham sido selecionados(as) para o cargo através de seleção pública realizada pela Secretaria Estadual de Saúde. Os(as) candidatos(as) foram submetidos(as) a uma prova de conhecimentos gerais e questões especificas sobre saúde. Nas primeiras seleções para o PACS, a condição de liderança comunitária contava ponto na classificação dos aprovados. Com o crescimento do Programa, essa condição foi sendo abandonada.

O treinamento contínuo, pressuposto na atividade, era desigual. Nas equipes mais consolidadas, os(as) agentes afirmaram ser constante (30), nas demais a freqüência era menor (21). As equipes em funcionamento há mais tempo, constituíram rotinas e mantinham treinamentos mais sistemáticos. As novas equipes, principalmente na capital do Estado, apresentavam problemas decorrentes da falta 
de infra-estrutura de funcionamento, uma vez que estavam sendo implantadas a "toque de caixa" para atender a fins eleitorais, segundo depoimentos. As sete primeiras equipes implantadas em 1999 na capital mantiveram-se até junho de 2002. A partir daí foram implantadas mais 93 equipes até agosto de 2003.

A Gestão Plena da Atenção Básica Ampliada (GPAB ou GPBA) ${ }^{8}$ na capital do Estado - NOAS/SUS 01/2001 (Norma Operacional de Assistência a Saúde do Ministério da Saúde) - define que em cidades que ofereçam serviços de alta complexidade, a gestão e relacionamento com os prestadores de alta complexidade são de responsabilidade do gestor estadual, o que significa estabelecer a autonomia de gestão das verbas do PSF e do atendimento nos três níveis: assistência básica, ambulatorial e hospitalar. Essa autonomia, por sua vez, possibilita maior interferência do poder executivo no Programa, na tentativa de utilizar os agentes comunitários em campanhas eleitorais e influir no processo seletivo desses trabalhadores.

As equipes do interior padeciam com a rotatividade de médicos e enfermeiros em busca de locações na capital ou em cidades maiores o que dificultava a normatização das atividades com o estabelecimento de rotinas.

A satisfação com o tipo de trabalho executado se manifestava no desejo declarado dos(as) agentes continuarem na atividade (46), embora estivessem insatisfeitos(as) (43) com os contratos de trabalho verbais e temporários. O caráter de formação contínua, de discussão com a equipe sobre o andamento do serviço, problemas e projetos a serem implementados, aumentam o envolvimento dos profissionais com a proposta do PSF e são vistos positivamente. Tanto é assim, que as associações e sindicatos de ACS tinham como bandeira, não apenas as questões contratuais, mas a permanência e ampliação do programa com base na formação continuada.

O pagamento dos salários era através de associações comunitárias, ou pela prefeitura e mantinham certa regularidade, embora sem nenhuma formalização, situação comum aos demais 
municípios do Estado. Em muitos municípios, entretanto, os atrasos nos pagamentos eram freqüentes pela utilização pelas prefeituras das verbas repassadas pelo Ministério da Saúde para outras atividades, desvios fraudulentos, etc. Em janeiro de 2002, 50 municípios paraibanos tiveram seus repasses suspensos por irregularidades, entre elas o não pagamento das equipes. Os agentes consideravam que com a regulamentação da profissão essa situação poderia ser alterada com o acesso à segurança no trabalho e direitos sociais o que efetivamente não aconteceu. Quase todos agentes entrevistados participavam de alguma associação ou sindicato de Agentes Comunitários de Saúde.

Entre os(as) 53 agentes entrevistados(as), 40 afirmaram que tinham algum tipo de atividade comunitária nas igrejas ou nas associações de bairros e praticamente todos(as) afirmaram atuar na comunidade, mesmo quando não especificavam o que faziam. Consideravam importante serem da comunidade para a realização desse tipo de trabalho, seja pela confiança e segurança que passavam aos moradores, seja pelo conhecimento que dispunham da comunidade e pela identificação com os problemas da população. No geral, reclamavam que um dos problemas do trabalho, em seus momentos iniciais era a rejeição por parte da comunidade das visitas e o descrédito com o Programa, situação superada posteriormente com a relativa consolidação das equipes e o funcionamento das Unidades de Saúde da Família.

A partir do momento que a comunidade entendia o PACS/ PSF, passava a exercer um efetivo controle social sobre o trabalho dos agentes, cobrando as visitas mensais e denunciando para as equipes aqueles que não as cumpriam. Além disso, a população tornase mais ciosa de seus direitos, cobrando mais por atendimento médico e medicamentos, tanto na forma proposta pelo PSF, quanto na forma tradicional de atendimento dos postos de saúde a que estavam acostumados (quando existiam postos de saúde anteriormente ao PSF). Esta situação incomodava um pouco os agentes e membros das equipes, principalmente quando atuavam em programas anteriores, desacostumados que estavam a esse tipo de controle. 
De qualquer forma, os(as) agentes percebiam que a partir do momento que começaram a trabalhar como Agentes Comunitários de Saúde melhorou seu status na comunidade. Reconheciam que o capital relacional de que dispunham facilitava o trabalho com a comunidade, tornava-os(as) respeitados(as) e referência para a população local.

A mobilização para obter melhorias da situação funcional tem resultado em avanços significativos para a categoria. É interessante observar que a atuação organizativa através, inicialmente, de federações que agrupavam associações, acompanha a atuação de outros profissionais de saúde pública, com discussões presentes em Conferências de Saúde, ponto de partida para reivindicações corporativas.

Na Paraíba, em 1992, foi criada a Associação Regional de Espinhares, no interior, a primeira do Estado. Em 1999, foi criada a Federação dos Agentes Comunitários de Saúde do Estado. Seus objetivos, além dos corporativos, visavam à consolidação do PACSPSF. Em agosto de 2002, foi criado o Sindicato dos Agentes Comunitários de Saúde, em João Pessoa, como resultado da regulamentação da profissão pelo governo federal.

Segundo uma liderança, a primeira bandeira de luta dos agentes foi a profissionalização, uma vez que a conquista de um contrato formal de trabalho parecia distante. No começo, existia a figura do trabalhador-bolsista, ${ }^{9}$ sem nenhum vínculo empregatício, situação posteriormente alterada com a expansão dos Programas. A ausência de contratos marcou momentos de luta pelo reconhecimento da categoria que culminou no decreto $n^{\circ}$ 3.189/99 e a elaboração de projeto de lei para regulamentar o exercício da profissão.

A necessidade de garantir direitos básicos resultou em negociações diretas com os gestores (o poder público local) e a conquista de 30 dias de férias no final do ano, licença à gestante, pagamento do salário mínimo e mais $40 \%$ de gratificação (embora não esteja generalizado a todos os agentes). Isso mesmo considerando que, nas normas diretrizes do PACS, o agente deveria ganhar apenas 
o salário mínimo. Os salários variavam de $\mathrm{R} \$ 240,00$ a $\mathrm{R} \$ 350,00$, sendo que os salários maiores referiam-se aos agentes com mais tempo de atividade, basicamente as primeiras sete equipes de João Pessoa. Esse é um ponto de reivindicação do sindicato dos Agentes Comunitários de Saúde, que queria passar todos os agentes para $\mathrm{R} \$ 350,00 .{ }^{10}$

A luta pela contratação permanece, embora não esteja definida a sua forma. Uma das reivindicações é a (improvável) contratação como funcionários públicos. As OCIPs eram vistas como possibilidades de garantir os direitos previstos na CLT, entretanto, algumas experiências com essas organizações foram problemáticas, como a de Fortaleza, no Ceará, implicada em processos de malversação de verbas. As cooperativas têm sido descartadas por serem difíceis de serem administradas, como a de Camaragibe, em Pernambuco, envolvendo todos os profissionais do PSF, que não foi exitosa, dada a resistência e o desinteresse dos trabalhadores autogerirem seu próprio trabalho.

Se para o agente comunitário de saúde o problema é o contrato, isso nem sempre acontece para profissionais como médicos e enfermeiros, odontólogos, assistentes sociais, ou mesmo auxiliares, que em alguns casos, são funcionários do Estado ou da prefeitura à disposição do PSF. Em outras situações, todos os profissionais enfrentam os mesmos contratos verbais de adesão.

Em linhas gerais, todas as formas propostas de contrato, como cooperativas, associações ou pela CLT, excluem o caráter "fordista" do emprego público e apontam para formas intermediárias de institucionalização que excluem a estabilidade do funcionalismo.

\section{Perspectivas}

A flexibilidade nas relações de trabalho vincula-se à reestruturação econômica das últimas décadas e aos seus rebatimentos no emprego público com as mudanças no Estado. A flexibilização é pensada como forma de adequação das relações de 
trabalho e organização da produção às novas tecnologias, assim como ao mercado de trabalho, salários e mobilidade dos trabalhadores. Já a precarização refere-se à degradação do trabalho sem considerar a possível valorização positiva que poderia ter um emprego "flexível" (Ramalho, 2000).

No caso da produção de bens e serviços de relevância social, como a saúde, o eixo da flexibilização não advém unicamente das necessidades de organizar a produção, mas também da necessidade de se pensar "ajustes" nas políticas públicas para reforçar o caráter de focalização, presente no PSF, que tensiona as propostas de universalização do SUS. A equação "neoliberalismo + focalização + perda de mecanismo de inclusão" não é linear, visto que em países com grande heterogeneidade social focalizar a pobreza pode ser uma forma de inclusão. No Brasil, a despeito da heterogeneidade, a focalização pode ser vista como forma de universalização. Nesta linha de argumentação, as políticas de saúde conseguem empreender uma maior universalização de cobertura, invertendo de certa forma o caráter perverso da exclusão por uma focalização com discriminação "positiva" (opção pelos excluídos, pelos de maior risco social etc.), embora em patamares mínimos de equidade.

Com a universalização da cobertura, cria-se a necessidade de organização de um mercado de trabalho que absorva um contingente de força de trabalho cujo preparo técnico possa ser efetuado com relativa "facilidade" e que não imponha um aumento dos custos sociais ao Estado. Por outro lado, adotam-se outros mecanismos que se apresentam com maior eficácia, como a maior autonomia na gestão de trabalho, o trabalho em equipe e a valorização da responsabilidade social, cuja perda tem sido atribuída, entre outros fatores, à cultura institucional do serviço público. ${ }^{11}$

Esta reflexão é importante para analisarmos o contexto na qual a novas institucionalidades no trabalho se impõem. Isso sem desconsiderarmos a perda de direitos que acarreta. Em termos de organização do trabalho, teríamos a flexibilidade "positiva" presente na grande margem de autonomia das equipes de trabalhadores e 
valorizados por fazerem parte da comunidade em que vivem, receberem formação continuada e participando ativamente da política de saúde desenvolvida em sua área de atuação. Como contrapartida teríamos, nas relações de trabalho, a flexibilidade "negativa", o predomínio de contratos temporários, parciais, e mesmo a inexistência de contrato algum. A ausência de direitos sociais afeta trabalhadores que, durante anos, mantiveram-se e mantêm-se com contratos "verbais" por tempo determinado sem nenhuma garantia. Do outro lado, temos a comunidade que passa a receber um serviço do qual sempre fora excluída, e mais: passa a controlar esse serviço, algo impensável anteriormente.

A amplitude do PSF/PACS em todo o País, entretanto, não permite generalizações excessivas. Devemos considerar que existiam aproximadamente 150.000 Agentes Comunitários de Saúde no Brasil, em 12.000 equipes do PSF, atuando em 4.000 municípios (dados de 2002) com tendência a aumentar, representando um potencial relevante em termos de emprego. Entretanto, esses empregos situam-se nas novas configurações do mercado com restrições ao acesso a direitos sociais vinculados ao contrato de trabalho tradicional.

Características relacionais são incorporadas agora como competências para os trabalhadores que devem trabalhar com a população. Quanto maior a participação das comunidades na elaboração e controle das políticas públicas, melhores poderão ser os resultados que também irão se refletir nas condições de trabalho das equipes de saúde. $\mathrm{O}$ funcionamento efetivo dos conselhos municipais de saúde e a redução do grau de interferência política do poder local constituem-se em fatores importantes, não apenas para os direitos do "consumidor" dos serviços prestados, mas dos direitos sociais dos trabalhadores envolvidos. A natureza participativa do trabalho em equipe pode se constituir em um fator a mais na busca de melhores condições de trabalho, portanto, trata-se de elemento importante para a redução dos efeitos negativos dessa flexibilização, além de melhorias concretas no atendimento à população. 


\section{Notas}

1 Os textos dos seminários encontram-se em Bresser Pereira e Grau (1999), Bresser Pereira e Spink (2001) e Bresser Pereira, Wilheim e Sola (1999), quando essa cobrança não existia ou não era considerada.

2 Existe todo um debate sobre a retomada do conceito de comunidade a partir dos anos 80 que ora contrapõe "comunitarismo" a liberalismo, ora os identificam. Entretanto, essa discussão extrapola os limites deste artigo.

3 Durkheim não chegou a utilizar propriamente o conceito, embora o tenha fundamentado ao discutir a coercitividade dos fatos sociais (1995). Sobre as origens do conceito, veja-se Boudon e Borricaud (1993).

4 Uma discussão sobre os limites do conceito e sua "mobilização" através dos Conselhos Municipais de Saúde no Brasil, encontra-se em Labra (2002).

5 Situação alterada com o reconhecimento da categoria profissional que estabeleceu a exigência de segundo grau completo para os novos agentes.

6 Quando não são funcionários deslocados para o PSF, são contratados por prefeituras, havendo uma rotatividade muito grande desses profissionais longe dos grandes centros urbanos.

7 PITS - Programa de Interiorização dos Trabalhadores em Saúde implantado pelo Ministério da Saúde, com profissionais selecionados pelo Ministério para atuarem nos Estados, em municípios do interior, com trabalho similar ao dos profissionais do PSF e é composto pela enfermeira e o médico. Os agentes comunitários que compõem a equipe são do PACS.

8 A outra forma de gestão prevista pela NOAS/SUS 01/2001 é a Gestão Plena do Sistema Municipal, que define um conjunto mínimo de procedimentos de média complexidade como primeiro nível de referência intermunicipal garantindo acesso a toda a população aos serviços de saúde no âmbito microrregional.

9 Bolsas de trabalho era (e em alguns lugares continua sendo) a forma de pagamento para evitar o vínculo empregatício.

10 Situação referente a João Pessoa; nos demais municípios o quadro é variável.

11 Agradeço a A. Uchôa pela contribuição na análise. 
Abstract: Nonstandard labor and social capital: the work of
Community Agents of Health in Paraíba State, Northeast of Brazil

This article aims to analyze the work of the community agents of health linked to two government programs: the Program of Community Agents of Health and the Program Health of the Family. The agents integrate workers' teams and their function are to transmit information about hygiene and health in the communities where they act, to lift data on incidence of diseases in the population and to direct the patients for service in the Unit of Health of the Family. For that they should be residents of the community, to do the link between community and the team. They are constituted in an atypical worker, be for the characteristics of the labor agreements (temporary, outsourcing, informal), be for the ownership of a social capital like demanded competence. In other words, a relational characteristic as condition to exercise the occupation. The work of the agents reflects the new forms of implementation of social policies decentralized by the State and the new forms of manpower use, out of the picture of the traditional civil servants. The research consisted from survey applied to 53 Community Agents of Health in twelve teams in João Pessoa, Campina Grande, Casserengue and Cacimba de Dentro; interviews with syndical leaderships, nurses, practitioners and state health managers.

Key-words: social control, social capital, nonstandard labor, Community Agents of Health.

\section{Referências bibliográficas}

ANDRADE, Ilza Araújo Leão de. A gestão participativa das políticas públicas: o desafio para os municípios do nordeste. In: O NORDESTE à procura da sustentabilidade. Rio de Janeiro: Fundação Conrad Adenauer, 2002. p. 51-68. (Cadernos Adenauer III, n.5).

BAUMAN, Zygmunt. Comunidade: a busca por segurança no mundo atual. Rio de Janeiro: Jorge Zahar, 2002.

BELLAH, Robert N. Comunitarismo ou liberalismo? Brasil e Estados Unidos em debate. In: SOUZA, Jessé. O malandro e o protestante: a tese weberiana e a singularidade cultural brasileira. Brasília: Editora Universidade de Brasília, 1999. p.295-315. 
BOURDIEU, Pierre. The forms of capital. (1986). In: FIELD, S. et al. Social capital: critical perspectives. Oxford University Press, 2000.

BOUDON, R.; BOURRICAUD, F. Controle social. In: BOUDON, R.; BOURRICAUD, F. Dicionário Crítico de Sociologia. São Paulo: Ática, 1993. p.100-106.

CARVALHO, Guido Viana; SANTOS, Lenir. Sistema Único de Saúde: comentários à Lei Orgânica da Saúde (Lei $8080 / 90$ e Lei 8 142/ 90). São Paulo: Editora Hucitec, 1992.

DURKHEIM, Émile. As regras do método sociológico. São Paulo: Martins Fontes, 1995. $165 \mathrm{p}$.

CASTELLS, Manuel. A sociedade em rede. São Paulo, Paz e Terra, 1999.

. Para o Estado-Rede:globalização econômica e instituições políticas na era da informação. In: PEREIRA, L. C. Bresser; WILHEM, Jorge; SOLA, Lourdes (Org.). Sociedade e Estado em transformação. São Paulo: Editora UNESP; Brasília: ENAP, 1999a.

COLLEMAN, James. Foundations of social theory. Cambridge, Mass: Harvard University Press, 1990.

GRANOVETTER, Mark. Getting a job: a study of contacts and careers. Chicago: The University of Chicago Press, 1995.

HARVEY, David. Condição pós-moderna: uma pesquisa sobre as origens da mudança cultural. São Paulo: Loyola, 1994.

LABRA, Maria Eliana. Social capital and health councils in Brazil: a virtuous circle? Cadernos de Saúde Pública, Rio de Janeiro, v. 18, supl., p.4755, jan. 2002.

MANFREDI, Silvia Maria. Trabalho, qualificação e competência profissional: das dimensões conceituais e políticas. Educação $e$ Sociedade, Campinas, v. 19, n. 64, set. 1998.

MENDES, Eugênio Vilaça (Org.). Distrito sanitário: processo social de mudança das práticas sanitárias do SUS. São Paulo: Hucitec; Rio de Janeiro: ABRASCO, 1993.

NOGUEIRA, Roberto P.; SILVA, Frederico Barbosa da; RAMOS, Zuleide do Valle O. A vinculação institucional de um trabalhador sui generis: o Agente Comunitário de Saúde. Rio de Janeiro: IPEA, 2000. (Texto para discussão, n. 735). 
NUNES, M. O. et al. O agente comunitário de saúde: construção da identidade desse personagem híbrido de polifônico. Cadernos de Saúde Pública, Rio de Janeiro, v. 18, n. 6, nov./dez. 2002.

PARAÍBA. Secretaria de Estado da Saúde. Relatório de gestão SES 1996/ 2002. João Pessoa, 2002.

PARAÍBA. Secretaria de Estado da Saúde. SIAB/SES. João Pessoa, junho, 2003.

PEREIRA, Luiz Carlos Bresser; GRAU, Nuria Cunill. Entre o Estado e o mercado: o público não-estatal. In: PEREIRA, Luiz Carlos Bresser; GRAU, Nuria Cunill. O público não-estatal na reforma do Estado. Rio de Janeiro: Editora Fundação Getúlio Vargas, 1999.

PEREIRA, Luiz Carlos Bresser; SPINK, P. Reforma do Estado e administração pública gerencial. Rio de Janeiro: Editora Fundação Getúlio Vargas, 2001.

PEREIRA, Luiz Carlos Bresser; WILHEIM, J.; SOLA, L. Sociedade e Estado em transformação. São Paulo: Editora UNESP; Brasília: ENAP, 1999.

PUTNAM, Robert D. Comunidade e democracia: a experiência da Itália moderna. Rio de Janeiro: Editora da Fundação Getulio Vargas, 2002.

RAMALHO, José Ricardo. Trabalho e sindicato: posições em debate na sociologia hoje. Dados, Rio de Janeiro, v. 43, n. 4, 2000.

SOUSA, Maria Fátima de. Agentes Comunitários de Saúde: choque de povo. São Paulo: HUCITEC, 2001.

TENDLER, Judith. Good government in the tropics. Baltimore: The Johns Hopkins University Press, 1997. 
